\title{
Hereditary neuropathy with liability to pressure palsies (HNPP) patients of Korean ancestry with chromosome 17p11.2-p12 deletion
}

\author{
Seung Min Kim ${ }^{1}$, Ki Wha Chung ${ }^{2}$ \\ Byung Ok Choi ${ }^{3,4}$, Eui Soo Yoon ${ }^{2}$ \\ Jung Young Choi ${ }^{2}$, Kee Duk Park \\ and II Nam Sunwoo \\ ${ }^{1}$ Department of Neurology \\ College of Medicine, Yonsei University \\ Seoul 120-752, Korea \\ ${ }^{2}$ Department of Biological Science \\ Kongju National University \\ Kongju 314-701, Korea \\ ${ }^{3}$ Department of Neurology and \\ Ewha Medical Research Center, College of Medicine \\ Ewha Womens University \\ Seoul 110-783, Korea \\ ${ }^{4}$ Corresponding author: Tel, 82-2-760-5257; \\ Fax, 82-2-760-5008; E-mail, bochoi@ewha.ac.kr \\ Accepted 10 December 2003
}

Abbreviations: CMAP, compound muscle action potential; CMT, Charcot-Marie-Tooth disease; CMT1A, Charcot-Marie-Tooth disease type $1 \mathrm{~A}$; DML, distal motor latency; FDS, functional disability scale; HNPP, hereditary neuropathy with liability to pressure palsies; MNCV, motor nerve conduction velocity; NCV, nerve conduction velocities; SNAP, sensory nerve action potential; SNCV, sensory nerve conduction velocity

\begin{abstract}
Hereditary neuropathy with liability to pressure palsies (HNPP) is an autosomal dominant inherited disorder characterized by recurrent pressure palsies. Most HNPP patients have a $1.5 \mathrm{mb}$ deletion in chromosome 17p11.2-p12. The present study aimed at evaluating the deletion of the 17p11.2-p12 region in Korean subjects with families exhibiting HNPP phenotype, and to determine the clinical, electrophysiological and morphological aspects specifically associated with this deletion in HNPP patients. By genotyping six microsatellite markers (D17S921, D17S955, D17S1358, D17S839, D17S122 and D17S261), HNPP with the deletion was observed in $79 \%$ (19 of 24 ) of HNPP families. Nerve conduction studies were performed in 35 HNPP pa-
\end{abstract}

tients from these 19 families. The observed HNPP deletion frequency in Koreans is consistent with findings in other populations. Disease onset occurred at a significantly earlier age in patients with recurrent pressure palsies than in those with a single attack $(P<0.01)$. Nerve conduction studies demonstrated diffuse mild to moderate slowing of nerve conduction velocities that were worse over the common entrapment sites, regardless of the clinical manifestations. A long duration of compound muscle action potentials without a conduction block or a temporal dispersion is a characteristic of this disease. A sural nerve biopsy with teasing was performed in four patients, and tomacula of the myelin sheath was found in $56.4 \%$. Our findings appear to support the existence of a phenotype/genotype correlation in HNPP patients of Korean ancestry with the deletion, and suggest that HNPP patients with earlier symptom onset face an increased chance of having recurrent attacks.

Keywords: Charcot-Marie-Tooth disease; hereditary motor and sensory neuropathies; hereditary sensory and autonomic neuroplathies; genotype; microsatellite repeats

\section{Introduction}

Hereditary neuropathy with liability to pressure palsies (HNPP) patients are characterized by recurrent pressure palsies and sausage-like swellings (tomacula) of the myelin sheaths by nerve biopsy (Behse et al., 1972). Deletion of the chromosome 17p11.2-p12 region including peripheral myelin protein 22 (PMP22) frequently provides the genetic basis of hereditary peripheral demyelinating neuropathy like HNPP (Verhagen et al., 1993; Guern et al., 1994). Mutations and the altered gene dosage of the PMP22 gene are regarded as the main reasons for hereditary peripheral neuropathies, and are found in approximately $80 \%$ of all cases (Mariman et al., 1994; Nelis et al., 1996; Timmerman et al., 1997). Deletion is the most frequent causative mutation, but is not found in all cases of HNPP (Chance et al., 1993). In rare cases, frame-shift mutations in the PMP22 gene lead to HNPP (Young et al., 1997).

Myelin plays an important role in the saltatory im- 
pulse transmission along neuronal extensions. Myelinforming Schwann cells entrap large-caliber axons with their plasma membranes during the development of the peripheral nervous system, as part of the process of myelination (Martini et al., 2001). Communication defaults between Schwann cells and neurons, due to genetic defects, frequently lead to these peripheral neuropathies (Lobsiger et al., 2002).

Recently, the identification of the genetic causes of peripheral neuropathies has been undertaken in various ethnic groups (Georgiou et al., 2002; Yoshihara et al., 2002; Hattori et al., 2003). In the present study, the deletion of the 17p11.2-p12 region was determined in Korean subjects with peripheral neuropathydiagnosed families. To detect the deletion, DNA samples were analyzed with six microsatellite markers, which were located within the $1.5 \mathrm{mb}$ region. In identified HNPP deletion families, clinical, electrophysiological and morphological characteristics of the disease were investigated.

\section{Materials and Methods}

\section{Samples and clinical assessment}

We performed mutational screening for the deletion in the chromosome 17p11.2-p12 region in 97 persons from 24 Korean HNPP families who were diagnosed clinically, electrophysiologically and pathologically. And we found 35 HNPP patients with chromosome $17 p$ 11.2-p12 deletion in 19 families. HNPP with the dele- tion was observed in $79 \%$ (19 of 24 ) of HNPP families. To compare HNPP patients with this deletion, we applied the clinical data of 34 previously diagnosed CMT1A patients with chromosome 17p11.2-p12 duplication.

The age of onset, duration of disease, functional disability scale (FDS), muscular atrophy, and foot deformity were examined to compare phenotypic differences between HNPP and CMT1A patients. Age of onset was determined by questioning HNPP patients about their age at first symptom onset, such as weakness, foot drop, wrist drop or sensory changes. We determined the disease severity of each patient according to a nine-point FDS, which was based on the following criteria: 0 , normal; 1 , normal but with cramps and fatigability; 2, inability to run; 3 , walking difficulty but still possible unaided; 4 , walk with cane; 5 , walk with crutches; 6, walk with a walker; 7, wheelchair bound; and 8 , bedridden.

\section{Amplification of six microsatellite markers}

DNA was extracted from collected whole blood or from buccal swabs. Informed consent was obtained from all individuals involved in this study. DNA extraction from blood was carried out using a genomic DNA isolation kit (CoreBio System, Korea). To extract DNA from the buccal swabs, we used the phenol:chloroform:isoamylalcohol method after proteinase $\mathrm{K}$ treatment at a final concentration of $0.3 \mathrm{mg} / \mathrm{ml}$ at $55^{\circ} \mathrm{C}$ for $3 \mathrm{~h}$.

Table 1. Microsatellite markers and PCR conditions used for the analysis of HNPP patients with chromosome 17p11.2-p12 deletion.

\begin{tabular}{|c|c|c|c|c|c|}
\hline \multicolumn{2}{|c|}{ Marker } & \multicolumn{4}{|c|}{ PCR condition } \\
\hline Name(Locus) & $\operatorname{Map}^{a}(c M)$ & Duplex PCR & Size $(b p)$ & Temp. $\left({ }^{\circ} \mathrm{C}\right)$ & Primer sequences $\left(5^{\prime} \rightarrow 3^{\prime}\right)$ \\
\hline D17S921 & 36.14 & I & $109-127$ & 65 & $\begin{array}{l}\text { F: GTGTTGTATTAGGCAGAGTTCTCC } \\
\text { R: CACCATAATCATGTCAGACAATCC }\end{array}$ \\
\hline D17S955 & 37.31 & II & $165-173$ & 62 & $\begin{array}{l}\text { F: GGTTGGGTGTCCTTGGCCTAC } \\
\text { R: ACTGGTGCATCCATGAGCATGC }\end{array}$ \\
\hline D17S1358 & & & $122-134$ & 62 & $\begin{array}{l}\text { F: AGCACCATGCCGGGCCACAC } \\
\text { R: AGATGGATAAGATGATCATGTTAC }\end{array}$ \\
\hline D17S839 & 37.8 & II & $123-143$ & 65 & $\begin{array}{l}\text { F: CAACAACAGCGAAACTCTGTCTC } \\
\text { R: AGACCCTGGAAGATCAACTACC }\end{array}$ \\
\hline D17S122 & & I & $153-167$ & 65 & $\begin{array}{l}\text { F: AGAACCACAAAAATGTCTTGCATTC } \\
\text { R: GGCCAGACAGACCAGGCTCTGC }\end{array}$ \\
\hline D17S261 & 41.12 & & $96-110$ & 62 & $\begin{array}{l}\text { F: CTAGGCACTGAAGCCAGGAAG } \\
\text { R: TTCTGGAAACCTACTCCTGAGC }\end{array}$ \\
\hline
\end{tabular}

\footnotetext{
a , Genetic distance (centi-Morgan) from the end of short arm.
} 
The six $(C A)_{n}$ repeat microsatellite markers (D17S122, D17S921, D17S955, D17S839, D17S261 and D17S 1358) localized in the duplication/deletion region of chromosome 17p11.2-p12 were amplified by PCR. The primer sequences for PCR amplification were as described by Mersiyanova et al. (2000). The genetic distance, primer sequences, annealing temperatures and PCR sizes are summarized in Table 1. PCR was carried out in $20 \mathrm{ml}$ of reaction mixture containing 10 $20 \mathrm{ng}$ DNA, $10 \mathrm{pmol}$ of each primer, $0.2 \mathrm{mM}$ of each nucleotide, $2 \mathrm{mM} \mathrm{MgCl} 2,0.6$ unit Taq DNA polymerase and $1 \times$ buffer (Promega) using a thermal cycler (Perkin Elmer 2700). Two set of duplex PCRs (duplex 1: D17S122 and D17S921; duplex 2: D17S955 and D17S839) were performed. Other two markers (D17S261 and D17S1358) were amplified by the single PCR method.

\section{Polyacrylamide gel electrophoresis and silver staining}

Electrophoresis was performed to genotype microsatel- lites in a $5 \%$ denaturing polyacrylamide (acrylamide: bisacryl amide $=19: 1)$ gel containing $7 \mathrm{M}$ urea in $1 \mathrm{x}$ TBE buffer (T: $0.4 \mathrm{~mm} \times \mathrm{L}: 40 \mathrm{~cm})$. PCR products were mixed with an equal volume of $2 \times$ STR loading buffer. Immediately after heating these mixtures at $95^{\circ} \mathrm{C}$ for $2 \mathrm{~min}$, they were chilled by submersion in ice. Electrophoresis was carried out at a constant $1,600 \mathrm{~V}$ for 2-4 $\mathrm{h}$.

DNA bands were visualized by the silver staining method described by Bassam et al. (1991) using a DNA silver staining kit (Promega). Gels were dipped into $10 \%$ ethanol for $20 \mathrm{~min}$, followed by a $1 \% \mathrm{HNO}_{3}$ solution for $10 \mathrm{~min}$. After treatment with staining solution (1 $\mathrm{g} \mathrm{AgNO}_{3}$ and $1.5 \mathrm{ml}$ of $37 \%$ formaldehyde/l) for $30 \mathrm{~min}$, the gels were rinsed with deionized water briefly (less than $20 \mathrm{~s}$ ), and then treated with a developer solution ( $30 \mathrm{~g} \mathrm{Na}_{2} \mathrm{CO}_{3}, 0.9 \mathrm{ml}$ of $37 \%$ formaldehyde and $0.5 \mathrm{ml}$ of $\left.1 \% \quad \mathrm{Na}_{2} \mathrm{~S}_{2} \mathrm{O}_{3} / \mathrm{l}\right)$. The reaction was stopped using a stop solution (10\% acetic acid) when the DNA bands appeared. The gels were gently agitated during each step.

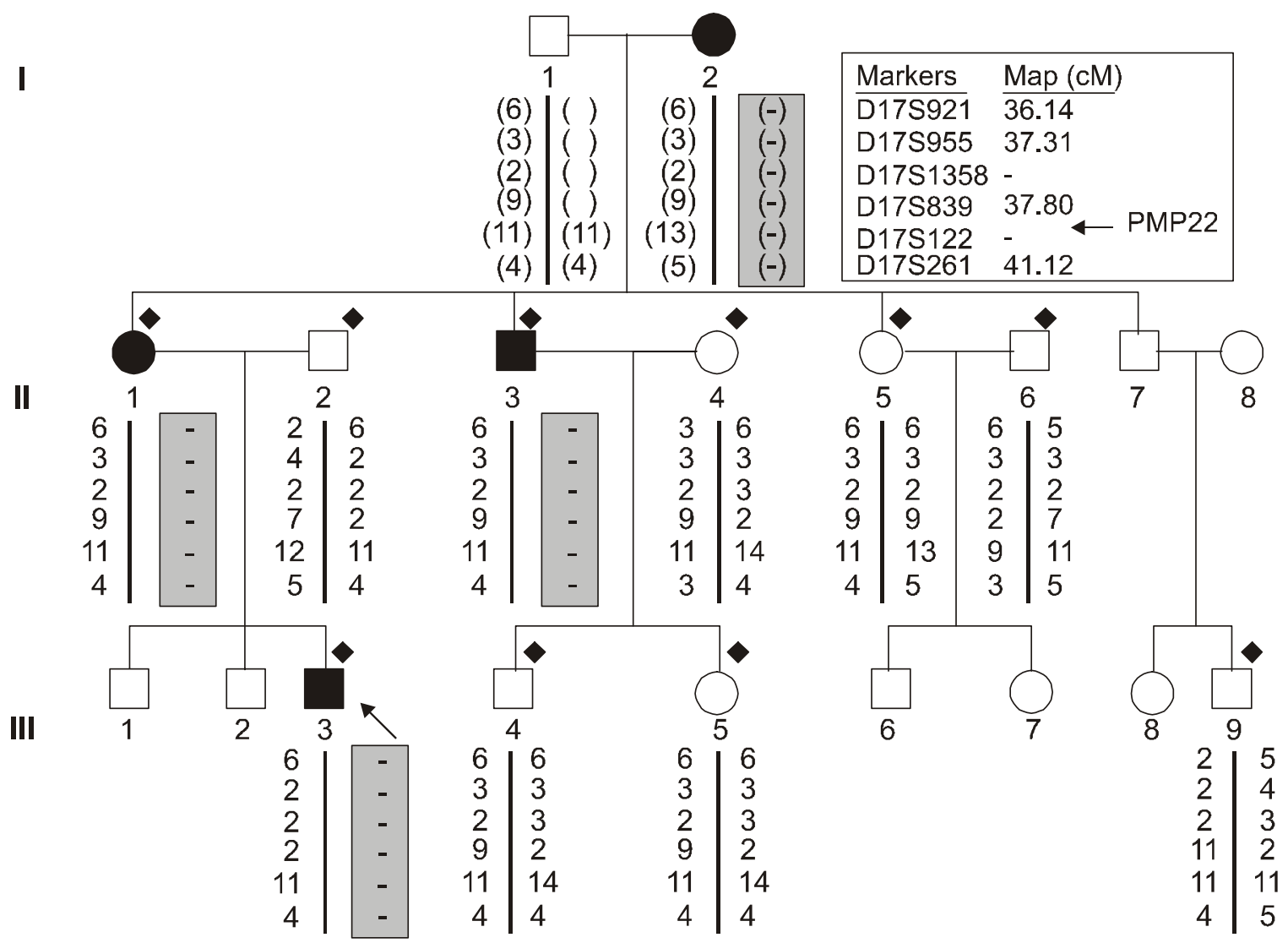

Figure 1. Pedigree of FC-81 with HNPP deletion. The open symbols stand for unaffected males $(\square)$ and unaffected females $(O)$. The filled symbols represent affected males $(\boldsymbol{\square})$ and affected females $(\mathbf{O})$. The diamonds $(\boldsymbol{\nabla})$ indicate persons whose DNA was used for the analysis with 6 microsatellites. Alleles of the individuals within parentheses were inferred. The arrow indicates the proband. The deletion of the six-marker region responsible for HNPP deletion is indicated by the shadowed box. 


\section{Electrophysiological and pathological analysis}

Nerve conduction studies were performed with surface stimulation and recording electrodes. Distal motor latency (DML), motor nerve conduction velocity (MNCV) and compound muscle action potential (CMAP) were recorded from the median, ulnar, peroneal and posterior tibial nerves in all patients. Sensory nerve action potential (SNAP) and sensory nerve conduction velocity (SNCV) were recorded for all patients over a fingerwrist segment from the median and the ulnar nerves. These were also recorded for the sural nerve.

Pathological examination of affected individuals included light and electron microscopic analysis and the teasing of a sural nerve biopsy from the left malleolus. Each specimen was fixed in buffered 2.5\% glutaraldehyde, post-fixed in osmium tetroxide, and embedded in epoxy resin. A portion of the biopsy was cut into semithin sections $(0.5 \mathrm{~mm})$, stained with toluidine blue for light microscopy and cut into ultra thin sections for electron microscopy. About one hundred single myelinated fibers were teased from the remainder of the nerve biopsy.

\section{Statistical analysis}

Percentages and means were compared using the Chi-square test and Student's $t$ test, respectively. Differences were considered significant when $P$ was $<$ 0.05 . Correlation studies were performed using single regression analysis, and correlations were considered significant when the correlation coefficient $r$ was $\geq 0.4$, and $P$ was $<0.05$. Analysis was performed using SPSS for Windows, version 11.0 (SPSS Inc., Chicago, Illinois).

\section{Results}

\section{Detection of deletion by genotyping of six microsatellites}

In HNPP deletion patients, genotyping of the six $(C A)_{n}$ repeat microsatellites located on the 17p11.2-p12 region was carried out by multiplex or single PCRs and denatured polyacrylamide gel electrophoresis. We considered individuals to have the HNPP-deletion when they were hemizygous for all markers. The allele densities were also considered to determine the hemizygisity.

In this study, D17S122 and D17S1358 were the most informative markers with heterozygosities of more than 0.7. The deletion was observed from 19 in 24 HNPP families, thus, the deletion frequency was calculated to 0.79 .

\section{Pedigree analysis of HNPP deletion}

An example of a HNPP family (Family ID: FC-81) is shown in Figure 1. In the proband (III-3: indicated by the arrow), only a single allele was detected for all the markers as the hemizygous state. The hemizygous haplotype of six markers in the proband was 6 (D17S921)-2 (D17S955)-2 (D17S1358)-2 (D17S839)11 (D17S122)-4 (D17S261). This haplotype was transmitted from his father, whereas no allele seemed to have originated from his mother. Hemizygosity was well matched with affected individuals (I-2, II-1, II-3 and III-3) by pedigree analysis of 10 family members. Unaffected members showed at least two markers having two different alleles. Members of the first generation (I-1 and I-2) were not analyzed, however, the deletion was

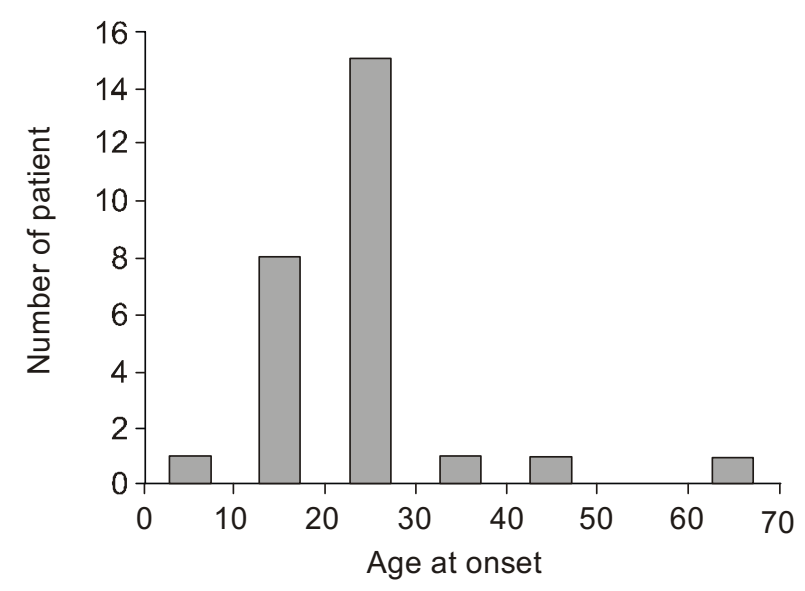

Figure 2. Frequency distribution of age at onset in 35 HNPP patients with chromosome 17p11.2-p12 deletion.

Table 2. Comparison of clinical aspects between 35 HNPP patients with chromosome 17p11.2-p12 deletion and 34 CMTIA patients with the duplication. Values are mean $\pm S D$, and percentages are in parentheses. HNPPa, HNPP patients with chromosome 17p11.2-p12 deletion; CMT1A $A^{b}$, CMT1A patients with chromosome 17p11.2-p12 duplication; FDSc, functional disability scale; ns, not significant.

\begin{tabular}{|c|c|c|c|}
\hline & HNPP $^{a}$ & $\mathrm{CMT}_{1} \mathrm{~A}^{\mathrm{b}}$ & Probability \\
\hline No. of patient & 35 & 34 & \\
\hline No. of male $(\%)$ & $29(82.9)$ & $13(38.2)$ & $P<0.01$ \\
\hline Onset age (year) & $25.6 \pm 13.6$ & $22.6 \pm 14.7$ & ns \\
\hline Disease duration (year) & $0.6 \pm 0.2$ & $9.9 \pm 6.6$ & $P<0.01$ \\
\hline \multicolumn{4}{|l|}{ FDSc $(\%)$} \\
\hline Low (0 or 1$)$ & $29(82.9)$ & $11(32.4)$ & $P<0.01$ \\
\hline Moderate (2) & $5(14.3)$ & $10(29.4)$ & $P<0.01$ \\
\hline High $(\geq 3)$ & $1(2.9)$ & $13(38.2)$ & $P<0.01$ \\
\hline \multicolumn{4}{|l|}{ Muscular atrophy (\%) } \\
\hline Upper extremity & $4(11.4)$ & $19(55.9)$ & $P<0.01$ \\
\hline Lower extremity & $1(2.9)$ & $29(85.3)$ & $P<0.01$ \\
\hline Foot deformity (\%) & $1(2.9)$ & $30(88.2)$ & $P<0.01$ \\
\hline No symptom $(\%)$ & $8(22.9)$ & $2(5.9)$ & $P<0.05$ \\
\hline
\end{tabular}


regarded to have originated from the grandmother $(I-2)$.

\section{Clinical findings}

Thirty-five HNPP patients with the deletion (29 males and 6 females) were studied. Mean age at onset was $25.6 \pm 13.6$ years. The frequency distribution of onset age is shown in Figure 2. The disease was transmitted from an affected father in 13 families $(68.4 \%)$, and from an affected mother in 4 families $(21.1 \%)$. Details of parental transmission were unknown in the remaining 2 cases $(10.5 \%)$.

The clinical differences between HNPP patients with the deletion, and CMT1A patients with the duplication are compared in Table 2. The affected states were considerably different in HNPP and CMT1A, even though both presented a demyelinating form. The average onset ages were not significantly different. However, the onset frequency of CMT1A at a preteen age was more than $20 \%$, while that of HNPP was only $2.9 \%$ (Figure 2). Disease duration was significantly longer in CMT1A (9.9 \pm 6.6 years) than in HNPP $(2.0 \pm 2.7$ years). The clinical symptoms, according to FDS, were more severe in CMT1A patients than in HNPP patients. The fraction of patients showing moderate or high level FDS $(\geq 2)$ were 0.62 in CMT1A and 0.17 in HNPP patients, respectively. An FDS score of 3 was the most frequent in CMT1A patients, and a score of 1 in HNPP patients. The percentages of patients with both muscular atrophy and foot deformity were significantly higher in CMT1A than in HNPP. Regression analysis derived scattering diagrams also showed different patterns between HNPP and CMT1A patients with respect to onset age and FDS. FDS was directly related to onset age in CMT1A $(r=0.81, P<0.01)$, but not in HNPP $(r=$ $0.07, P=0.71$ ) (Figure 3). Asymptomatic patients who were diagnosed only by genetic analysis were more frequently found to have a deletion in HNPP than a duplication in CMT1A $(P<0.05)$.

In addition, we compared the clinical and electrophysiological characteristics of HNPP patients who had experienced between single and recurrent attacks (Table 3), and found that patients who had experi-

Table 3. Comparison of the clinical and electrophysiological aspects of HNPP patients who had experienced a single attack and those who had experienced recurrent attacks. Values are mean $\pm S D$, and percentages are in parentheses. FDS ${ }^{\mathrm{a}}$, functional disability scale; DML, distal motor latency; CMAP, compound muscle action potential; MNCV, motor nerve conduction velocity; SNAP, sensory nerve action potential; SNCV, sensory nerve conduction velocity; ns, not significant.

\begin{tabular}{|c|c|c|c|}
\hline Frequency & $\begin{array}{l}\text { Single } \\
\text { attack }\end{array}$ & $\begin{array}{l}\text { Recurrent } \\
\text { attacks }\end{array}$ & Probability \\
\hline No. of patients & 16 & 19 & $\cdots$ \\
\hline No. of male $(\%)$ & $13(81.3)$ & $16(84.2)$ & ns \\
\hline Onset age & $33.4 \pm 16.4$ & $18.9 \pm 4.9$ & $P<0.01$ \\
\hline \multicolumn{4}{|l|}{ FDS $^{a}(\%)$} \\
\hline Low (0 or 1 ) & $13(81.3)$ & $16(84.2)$ & ns \\
\hline Moderate (2) & $2(12.5)$ & $3(15.8)$ & ns \\
\hline High $(\geq 3)$ & $1(6.3)$ & $0(0.0)$ & $\cdots$ \\
\hline \multicolumn{4}{|l|}{ Median nerve } \\
\hline DML (ms) & $5.1 \pm 1.0$ & $5.1 \pm 1.2$ & ns \\
\hline CMAP (mV) & $12.2 \pm 4.3$ & $12.4 \pm 4.9$ & ns \\
\hline $\operatorname{MNCV}(\mathrm{m} / \mathrm{s})$ & $48.8 \pm 7.7$ & $52.4 \pm 3.9$ & ns \\
\hline \multicolumn{4}{|l|}{ Sural nerve } \\
\hline SNAP (mV) & $12.0 \pm 5.6$ & $13.3 \pm 5.5$ & ns \\
\hline SNCV $(\mathrm{m} / \mathrm{s})$ & $30.5 \pm 5.4$ & $30.6 \pm 4.5$ & ns \\
\hline
\end{tabular}

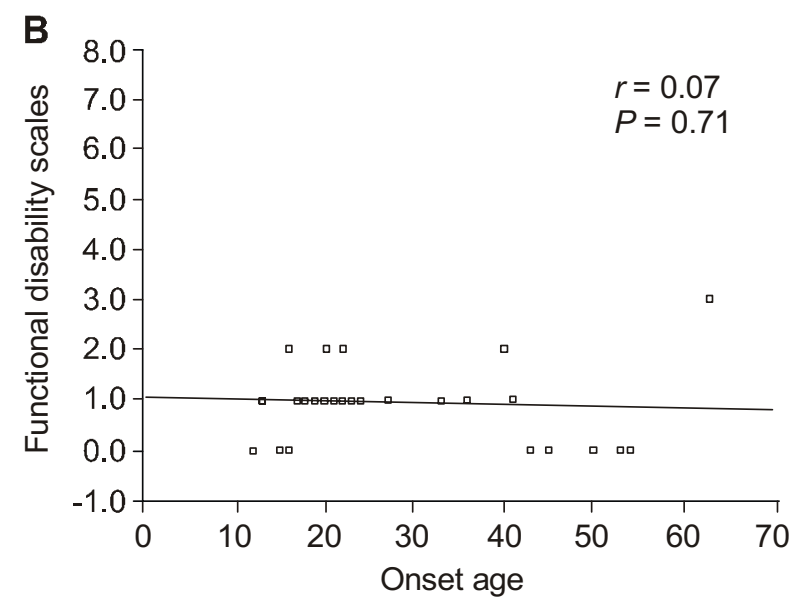

Figure 3. Scatter diagrams used for regression analysis between onset age and FDS scores in (A) 34 CMT1A patients with the duplication, and in (B) 35 HNPP patients with the deletion. 
Table 4. Electrophysiological testing abnormalities of HNPP patients with chromosome 17p11.2-p12 deletion. Values are mean $\pm S D$, and percentages are in parentheses. DML, distal motor latency; CMAP, compound muscle action potential; MNCV, motor nerve conduction velocity; SNAP, sensory nerve action potential; SNCV, sensory nerve conduction velocity.

\begin{tabular}{|c|c|c|c|}
\hline & Mean $\pm S D$ & Ranqe & Abnormal $(\%)$ \\
\hline \multicolumn{4}{|c|}{ Median motor nerve } \\
\hline DML (ms) & $5.1 \pm 1.1$ & $3.1-9.3$ & $31(88.6)$ \\
\hline CMAP $(\mathrm{mV})$ & $12.3 \pm 4.5$ & $4.0-24.0$ & $2(5.7)$ \\
\hline $\operatorname{MNCV}(\mathrm{m} / \mathrm{s})$ & $50.7 \pm 6.1$ & $27.3-58.7$ & $13(37.1)$ \\
\hline \multicolumn{4}{|c|}{ Ulnar motor nerve } \\
\hline DML (ms) & $3.5 \pm 0.6$ & $2.5-5.0$ & $24(68.6)$ \\
\hline CMAP $(\mathrm{mV})$ & $12.6 \pm 3.3$ & $3.9-19.4$ & $2(5.7)$ \\
\hline $\operatorname{MNCV}(\mathrm{m} / \mathrm{s})$ & $49.2 \pm 7.2$ & $28.3-59.7$ & $18(51.4)$ \\
\hline \multicolumn{4}{|l|}{ Peroneal nerve } \\
\hline DML (ms) & $7.0 \pm 1.9$ & $3.7-12.0$ & $26(74.3)$ \\
\hline CMAP $(\mathrm{mV})$ & $4.3 \pm 2.7$ & $0.4-9.6$ & $7(20.0)$ \\
\hline $\operatorname{MNCV}(\mathrm{m} / \mathrm{s})$ & $36.8 \pm 6.4$ & 21.1-57.1 & $26(74.3)$ \\
\hline \multicolumn{4}{|c|}{ Posterior tibial nerve } \\
\hline DML (ms) & $4.9 \pm 1.1$ & $3.1-7.5$ & $10(28.6)$ \\
\hline CMAP $(\mathrm{mV})$ & $15.5 \pm 6.0$ & $2.5-28.8$ & $2(5.7)$ \\
\hline $\operatorname{MNCV}(\mathrm{m} / \mathrm{s})$ & $41.2 \pm 6.0$ & $21.8-51.5$ & $15(42.9)$ \\
\hline \multicolumn{4}{|c|}{ Median sensory nerve } \\
\hline SNAP (mV) & $14.6 \pm 11.4$ & $2.3-53.2$ & $12(34.3)$ \\
\hline SNCV $(\mathrm{m} / \mathrm{s})$ & $32.5 \pm 7.7$ & $22.3-54.0$ & $31(88.6)$ \\
\hline \multicolumn{4}{|c|}{ Ulnar sensory nerve } \\
\hline SNAP (mV) & $12.5 \pm 11.4$ & $2.1-57.0$ & $14(40.0)$ \\
\hline SNCV (m/s) & $32.0 \pm 6.5$ & $18.2-49.7$ & 29 (82.9) \\
\hline \multicolumn{4}{|l|}{ Sural nerve } \\
\hline SNAP (mV) & $12.8 \pm 5.5$ & $2.3-23.8$ & $4(11.4)$ \\
\hline $\operatorname{SNCV}(\mathrm{m} / \mathrm{s})$ & $30.6 \pm 4.8$ & $22.5-41.5$ & $25(71.4)$ \\
\hline
\end{tabular}

enced recurrent attacks showed a significantly earlier onset age $(P<0.01)$. However, there were neither electrophysiological nor functional differences between the two sets of patients.

\section{Electrophysiological and pathological findings}

All thirty-five patients showed a marked slowing of motor and sensory nerve conduction (Table 4). The MNCVs in this study were frequently reduced, for example, in $74.3 \%$ of cases in terms of peroneal nerve conduction. Also, the distal motor latency was prolonged in the median nerve (88.6\%). Neither a conduction block nor a temporal dispersion of action potentials was exhibited in this study.
SNAP and SNCV were abnormal in many patients tested. Finger-wrist segments of the median and the ulnar nerves recorded abnormal results in more than $80 \%$ of HNPP deletion patients.

When we compared symptomatic and asymptomatic sites in patients showing a deletion in the 17p11.2-p12 region, nerve conduction studies demonstrated diffuse mild to moderate slowing of NCV that was noticeable worse over the common entrapment sites, regardless of the clinical manifestations.

Sural nerve biopsy was performed in four patients with the deletion. Histopathologic examinations showed relatively preserved density of myelinated fibers. No onion bulb formation was found. Teased fiber analysis confirmed the presence of focally folded myelin (tomacula) about $56.4 \%$. The histopathologic findings were consistent with tomacula neuropathy in all biopsied patients (Figure 4).

\section{Discussion}

HNPP with deletion is the reciprocal product of an unequal crossing-over event within the chromosome 17p11.2-p12 region. By mutational screening of HNPP families, the deletion was found in 35 patients from 19 families (79\%) among 24 HNPP diagnosed families. This frequency of HNPP with the deletion in Korean patients is consistent with the range of 72 to $86 \%$ reported in other populations (Mariman et al., 1994; Nelis et al., 1996; Timmerman et al., 1997). HNPP is known as a genetically homogeneous disease compared with CMT, though frame-shift mutations in the PMP22 gene lead to HNPP in rare cases (Young et al., 1997). Thus, causative mutations in PMP22 are expected in the $21 \%$ of HNPP patients with no deletion. In addition, it is possible that unknown genes are related to HNPP patients in Koreans. The detection of HNPP deletion in this study would be helpful for the further analysis of the genetic and pathophysiologic causes of peripheral neuropathies.

We investigated the clinical differences between 35 HNPP patients with chromosome 17p11.2-p12 deletion and 34 CMT1A patients with these duplication. The clinical assessments of HNPP patients were generally less severe than those of CMT1A patients. HNPP usually develops as a painless neuropathy after minor trauma or compression (Gouider et al., 1994; Pareyson et al., 1996). The mean onset ages between HNPP and CMT1A were not significantly different. However, onset in the pre-teens was found to be seven times more frequent in CMT1A than in HNPP. Several clinical symptoms, such as disease duration, muscular atrophy, and foot deformity indicated that CMT1A patients were more severely affected than HNPP patients. FDS values also implied the greater 

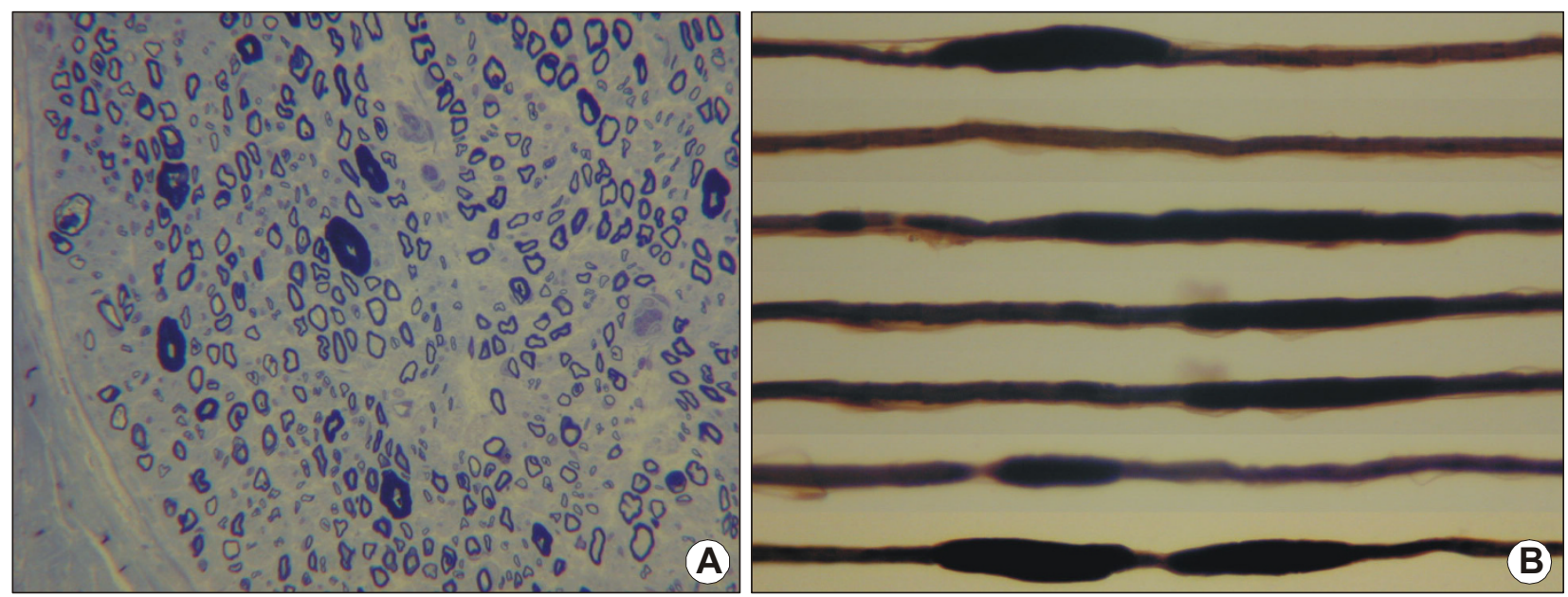

Figure 4. Transverse semithin section of sural nerve. Thickening of myelin sheath (tomacula) are occasionally seen (A, Toluidine blue, x400). Consecutive lengths along one teased myelinated fiber from the sural nerve of a patient with HNPP demonstrates multiple characteristic tomacula (B, Osmium tetroxide, $\times 400)$.

severity of CMT1A. The frequency of patients with a moderate or high level of FDS was 0.17 and 0.62 in each HNPP and CMT1A. We also found that the FDS was related to the onset age in CMT1A, but not in HNPP (Figure 3). Thus, it seems that the FDS is a more useful scale for CMT1A.

Clinical symptoms of HNPP appeared at less than thirty years of age in more than $88 \%$ of cases. In addition, the percentage of male patients in HNPP was found to be more than $80 \%$. In Korea, most men conscripted to the military for 3 years in their third decade. Military service might explain why most HNPP patients in Korea develop pressure palsies during this period. Perhaps nerve compression due to military training or greater physical activity is directly related to disease onset.

Eight $(22.9 \%)$ of HNPP patients with the deletion were asymptomatic and diagnosed only by genetic analysis, which agrees with the results of previous studies (Mariman et al., 1994; Pareyson et al., 1996). So, it would be necessary to perform nerve conduction studies and genetic analyses in asymptomatic family members.

In most patients, prolonged distal motor latency and a slow MNCV in the carpal tunnel area of the median nerve showed that those sites are liable to suffer myelin damage by nerve compression. In other words, HNPP patients, with congenital abnormalities for compact myelin, easily damage the peripheral nervous system by external compression. Those phenomena differ from both CMT1A and acquired demyelinating neuropathy (Airaksinen et al., 1985; Maritinelli et al., 1989; Uncini et al., 1995).

It is well known that both conduction block and temporal dispersion are the electrophysiological charac- teristics of demyelinating neuropathy (Behse et al., 1972; Chance et al., 1994; Uncini et al., 1995). However, all HNPP patients in this study showed a long duration of compound muscle action potentials without a conduction block or a temporal dispersion. These findings differentiate HNPP from both CMT1A and acquired demyelinating neuropathy. In addition, nerve conduction studies demonstrated diffuse slowing of NCV, which was notably worse over common entrapment sites, regardless of the clinical manifestations. Moreover, the electrophysiological findings were frequently more severe in the asymptomatic side than in the symptomatic state. Therefore, in HNPP patients, it was relatively common that clinical symptoms were not in accord with electrophysiological abnormalities. These findings show that the clinical manifestations of HNPP are more related to nerve compression than congenital demyelination.

When we compared HNPP patients, who had experienced a single attack or recurrent attacks, we found that the latter had a lower age of onset. Interestingly, these findings indicate the possibility that an indivisual with early symptom onset has a higher likelihood of recurrence. These findings have not been reported previously. The identification of prognostic indicators and a correct diagnosis might help to prevent recurrent attacks. Though these hypotheses require further prospective studies, these results indicate that who experience the clinical symptoms of HNPP at an early age must take precautions to nerve compression.

Even though tomacula is not specific, it is the most pathognomonic finding of HNPP in a nerve biopsy (Bradley et al., 1975; Jacobs and Gregory, 1991). In this study, we found that tomacula is present in about $56.4 \%$ of cases. The reason for the presence of to- 
macula is not known, however, the observation of tomacula is useful in the diagnosis of HNPP.

We report upon the clinical, electrophysiological and morphological aspects of the Korean HNPP patients with deletion. In addition, our findings suggest the possibility that HNPP patients with an earlier symptom onset face an increased likelihood of recurrent attacks.

\section{Acknowledgment}

This study was supported by the research fund (\#R052003-000-11496-0) from KOSEF, and Kongju National University (2003).

\section{References}

Airaksinen EM, Livanainen M, Karil P, Sainio K, Haltia M. Hereditary recurrent brachial plexus neuropathy with dysmorphic features. Acta Neurol Scand 1985;71:309-16

Bassam SJ, Caetano-Anolles G, Gresshoff PM. Fast and sensitive silver staining of DNA in polyacrylamide gels. Anal Biochem 1991;196:80-3

Behse F, Buchthal F, Carlsen F, Knappeis GG. Hereditary neuropathy with liability to pressure palsies. Brain 1972;95:777-94

Bradley WG, Madrid R, Thrush DC, Campbell MJ. Recurrent brachial plexus neuropathy. Brain 1975;98:381-98

Chance PF, Alderson MK, Leppig KA, Lensch MW, Matsunami N, Smith B, Swanson PD, Odelberg SJ, Distsche CM, Bird TD. DNA deletion associated with hereditary neuropathy with liability to pressure palsies. Cell 1993;72:143-51

Chance PF, Lensch MW, Lipe H, Brown RH Sr, Brown RH $\mathrm{Jr}$, Phil D, Bird TD. Hereditary neuralgic amyotrophy and hereditary neuropathy with liability to pressure palsies: two distinct genetic disorders. Neurology 1994;44:2253-7

Georgiou DM, Zidar J, Korosec M, Middleton LT, Kyriakides T, Christodoulou K. A novel NF-L mutation Pro22Ser is associated with CMT2 in a large Slovenian family. Neurogenetics 2002:4:93-6

Gouider R, LeGuern E, Emile J, Tardieu S, Cabon F, Samid M, Weissenbach J, Agid Y, Bouche P, Brice A. Hereditary neuralgic amyotrophy and hereditary neuropathy with liability to pressure palsies: two distinct clinical, electrophysiologic, and genetic entities. Neurology 1994;44:2250-2

Hattori N, Yamamoto M, Yoshihara T, Koike H, Nakagawa M, Yoshikawa H, Ohnishi A, Hayasaka K, Onodera O, Baba M, Yasuda H, Saito T, Nakashima K, Kira J, Kaji R, Oka N, Sobue G; Study Group for Hereditary Neuropathy in Japan. Demyelinating and axonal features of Charcot-MarieTooth disease with mutations of myelin-related proteins (PMP22, MPZ and Cx32): a clinicopathological study of 205 Japanese patients. Brain 2003;126:134-51

Jacobs JM, Gregory R. Uncompacted lamellae as a feature of tomaculous neuropathy. Acta Neuropathol 1991;83:87-91

Le Guern E, Sturtz F, Gugenheim M, Gouider R, Bonnebouche C, Ravise N, Gonnaud PM, Tardieu S, Bouche P,
Chazot G. Detection of deletion within 17p11.2 in 7 French families with hereditary neuropathy with liability to pressure palsies (HNPP). Cytogenet Cell Genet 1994;65:261-4

Lobsiger CS, Taylor V, Suter U. The early life of a Schwann cell. Biol Chem 2002;383:245-53

Mariman EC, Gabreels-Festen AA, van Beersum SE, Valentijn LJ, Baas F, Bolhuis PA, Jongen PJ, Ropers HH, Gabreels FJ. Prevalence of the 1.5-Mb 17p deletion in families with hereditary neuropathy with liability to pressure palsies. Ann Neurol 1994;36:650-5

Maritinelli $P$, Fabbri R, Moretto G, Gabellini AS, D'Alessandro $R$, Rizzuto N. Recurrent familial brachial plexus palsies as the only clinical expression of 'tomaculous' neuropathy. Eur Neurol 1989;29:61-6

Martini R. The effect of myelinating Schwann cells on axons. Muscle Nerve 2001;24:456-66

Mersiyanova IV, Ismailov SM, Polyakov AV, Dadali EL, Fedotov VP, Nelis E, Lofgren A, Timmerman V, van Broeckhoven $C$, Evgrafov OV. Screening for in the peripheral myelin genes PMP22, MPZ and Cx32 (GJB1) in Russian CharcotMarie-Tooth Neuropathy patients. Hum Mutat 2000;15:340-7

Nelis E, Van Broeckhoven C, De Jonghe P, Lofgren A, Vandenberghe A, Latour $P$, Le Guern E, Brice A, Mostacciuolo ML, Schiavon F, Palau F, Bort S, Upadhyaya M, Rocchi M, Archidiacono N, Mandich P, Bellone E, Silander K, Savontaus ML, Navon R, Goldberg-Stern H, Estivill X, Volpini V, Friedl W, Gal A. Estimation of the mutation frequencies in Charcot-Marie-Tooth disease type 1 and hereditary neuropathy with liability to pressure palsies: a European collaborative study. Eur J Hum Genet 1996;4:25-33

Pareyson D, Scaioli V, Taroni F, Botti S, Lorenzetti D, Solari A, Ciano C, Sghirlanzoni A. Phenotypic heterogeneity in hereditary neuropathy with liability to pressure palsies associated with chromosome 17p11.2-12 deletion. Neurology 1996; 46:1133-7

Timmerman V, Rautenstrauss B, Reiter LT, Koeuth T, Lofgren A, Liehr T, Nelis E, Bathke KD, De Jonghe $P$, Grehl $\mathrm{H}$, Martin JJ, Lupski JR, Van Broeckhoven C. Detection of the CMT1A/HNPP recombination hotspot in unrelated patients of European descent. J Med Genet 1997;34:43-9

Uncini A, Di Guglielmo G, Di Muzio A, Gambi D, Sabatelli $M$, Mignogna $T$, Tonali $P$, Marzella $R$, Finelli $P$, Archidiacono N. Differential electrophysiological features of neuropathies associated with 17p11.2 deletion and duplication. Muscle Nerve 1995;18:628-35

Verhagen WI, Gabreels-Festen AA, van Wensen PJ, Joosten EM, Vingerhoets HM, Gabreels FJ, de Graaf R. Hereditary neuropathy with liability to pressure palsies: a clinical, electroneurophysiological and morphological study. J Neurol Sci 1993;116:176-84

Yoshihara T, Yamamoto M, Hattori N, Misu K, Mori K, Koike $\mathrm{H}$, Sobue G. Identification of novel sequence variants in the neurofilament-light gene in a Japanese population: analysis of Charcot-Marie-Tooth disease patients and normal individuals. J Peripher Nerv Syst 2002;7:221-4

Young $P$, Wiebusch $H$, Stogbauer $F$, Ringelstein $B$, Assmann $G$, Funke $H$. A novel frameshift mutation in PMP22 accounts for hereditary neuropathy with liability to pressure palsies. Neurology 1997;48:450-2 